\title{
Uso do nitrato de cério associado ao colágeno e alginato de cálcio no tratamento das queimaduras: uma série de casos
}

\section{Use of cerium nitrate associated with collagen and calcium alginate in burns treatment: case series}

José Aldari Lima ${ }^{1} \bullet$ Roberta Araújo Montana² •

\begin{abstract}
RESUMO
Introdução: 0 tratamento das queimaduras é considerado um grande desafio para os profissionais da área de saúde. Cada vez mais, a indústria produz e disponibiliza para o mercado novos produtos com tecnologia inovadora para tratamento de lesões, que permitem redução do número de trocas dos curativos e da dor, maior conforto e que aceleram o processo de reparo tecidual da pele. 0 objetivo deste estudo foi avaliar o processo de reparo tecidual de queimaduras de $2^{\circ}$ grau superficial e intermediário em uso de um curativo biológico composto por nitrato de cério, colágeno bovino e alginato de cálcio. Método: Trata-se de uma série de seis casos. A coleta de dados foi realizada de dezembro de 2013 a maio de 2014, por médicos e enfermeiros do Centro de Tratamento de Queimados de um hospital municipal do Rio de Janeiro/RJ. Resultados: Em todos os casos acompanhados as queimaduras apresentaram melhora no processo de reparo tecidual e da dor e não foram evidenciados sinais clínicos de infecção durante as trocas de curativos. Conclusão: 0 uso de um curativo biológico e de alta tecnologia, aliado ao cuidado especializado do paciente queimado, trazem mais benefícios para o processo de cicatrização da queimadura e para a saúde do paciente.
\end{abstract}

Descritores: Queimaduras; Cicatrização; Ferimentos e Lesões.

\begin{abstract}
Introduction: Burns treatment is still a major challenge for health professionals. Increasingly, industry produces and provides to the market, new products with innovative technology for the treatment of lesions that enable reduction in the number of dressing changes and pain, increase comfort and accelerate the skin tissue repair process. The aim of this study was to evaluate the tissue repair process of superficial and intermediate 2 nd degree burns with the use of a biological dressing composed of cerium nitrate, bovine collagen and calcium alginate. Method: This is a series of 06 cases. Data collection was conducted from December 2013 to May 2014 by doctors and nurses from the Burn Treatment Center of a Rio de Janeiro Municipal Hospital. Results: In all cases followed, burns showed improvement in tissue repair process and pain and have not shown clinical signs of infection during dressing changes. Conclusion: We conclude that the use of a high technology biological dressing combined with burned patients specialized care, brings greater benefits to the healing process of burns and also for patient health.
\end{abstract}

Keywords: Burns; Wound Healing, Wounds and Injuries

1,2 Médicos do Centro de Tratamento de Queimados - Hospital Municipal Souza Aguiar, Rio de Janeiro, RJ.

Os autores declaram não haver conflitos de interesse. 


\section{INTRODUÇÃO}

A queimadura é considerada um trauma de grande complexidade, de difícil tratamento e com alta taxa de morbidade e mortalidade. ${ }^{1-5} \mathrm{~A}$ maioria dos casos de queimaduras ocorre em um cenário doméstico ou de trabalho, envolvendo crianças ou adultos, como resultado de violência interpessoal. ${ }^{5}$

0 tratamento das queimaduras ainda constitui um grande desafio para os profissionais da área de saúde. ${ }^{6}$ Cada vez mais, a indústria apresenta novos produtos para tratamento de feridas, que permitem menor número de trocas, redução da dor, maior conforto e reparo tecidual.

No caso das queimaduras, ressalta-se a importância do preparo do leito nos casos de lesões que necessitam de enxertia de pele, o combate da infecção, a imunomodulação e o controle da dor. ${ }^{2}$

Em setembro de 2013, foi lançado um novo produto pelo Laboratório Silvestre Labs ${ }^{\circledR}$ associando os benefícios do nitrato de cério ao colágeno bovino e ao alginato de cálcio. Esse curativo biológico visa a controlar a colonização bacteriana, absorver exsudato de quantidade pequena a moderada e promover a aceleração do processo de cicatrização da pele.

Esse curativo biológico é indicado para queimaduras e feridas de difícil cicatrização, como as sanguinolentas, a úlcera de perna e a úlcera de pressão e pé diabético, complicação grave do diabetes. Nas não deve ser utilizado em pacientes com conhecida hipersensibilidade aos componentes de sua formulação. Deve-se interromper a sua utilização se surgirem quaisquer sinais de sensibilidade.

Deve ser aplicado sobre a área da lesão, devendo cobrir toda a extensão da mesma, podendo ser cortados com tesoura estéril, quando necessário.

O objetivo deste estudo foi avaliar o processo de reparo tecidual de queimaduras de $2^{\circ}$ grau superficial e intermediário em uso de um curativo biológico composto por nitrato de cério, colágeno bovino e alginato de cálcio.

A relevância desse estudo está na indicação de um curativo biológico inovador composto por três coberturas (nitrato de cério, colágeno bovino e alginato de cálcio) para o tratamento de queimaduras, considerando que suas principais vantagens são: diminuir a colonização bacteriana, reduzir a dor, otimizar o meio para uma boa cicatrização e ser de fácil aplicação.

\section{RELATO DE CASOS}

Caso 1: Paciente de 43 anos, sexo masculino, vítima de queimadura por arco voltaico, apresentando $6 \%$ de superfície corpórea queimada de segundo grau superficial e em algumas áreas de segundo grau profundo. Acometendo membro superior esquerdo. Foi internado no CTQ em 19/12/2013, logo após o acidente. O primeiro curativo com a associação de nitrato de cério, colágeno e alginato de cálcio foi realizado no dia subsequente, 20/12/2013.
As trocas foram sequenciais em 23/12/2013 (figura 1A) e 26/12/2013 (a cada 3 dias)(figura 1B). 0 processo de cura foi concluído no dia 31/12/2013 (12 dias) e a documentação fotográfica final foi no dia 07/01/2014 (19 dia pós-queimadura - figura 1C). 0 paciente apresentou mínima dor às trocas e a equipe considerou fácil o manejo dos curativos. Não foram evidenciados sinais clínicos de infecção.

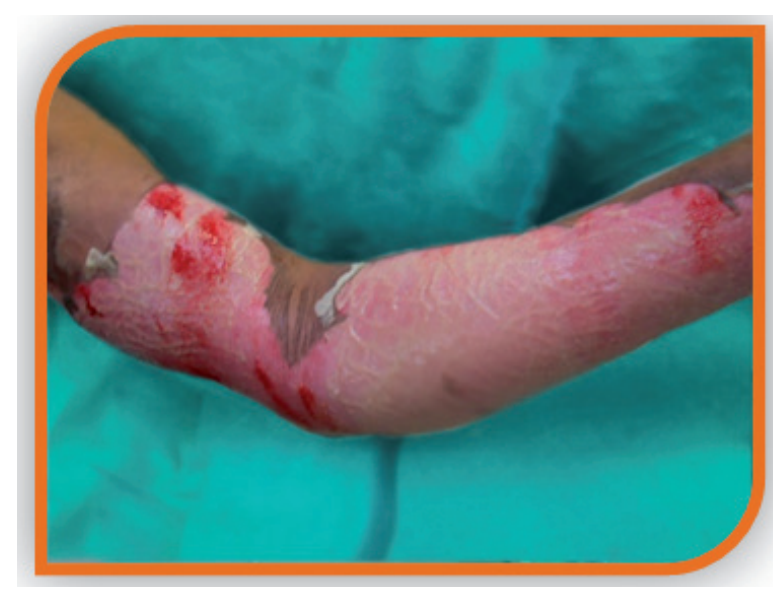

Figura 1A

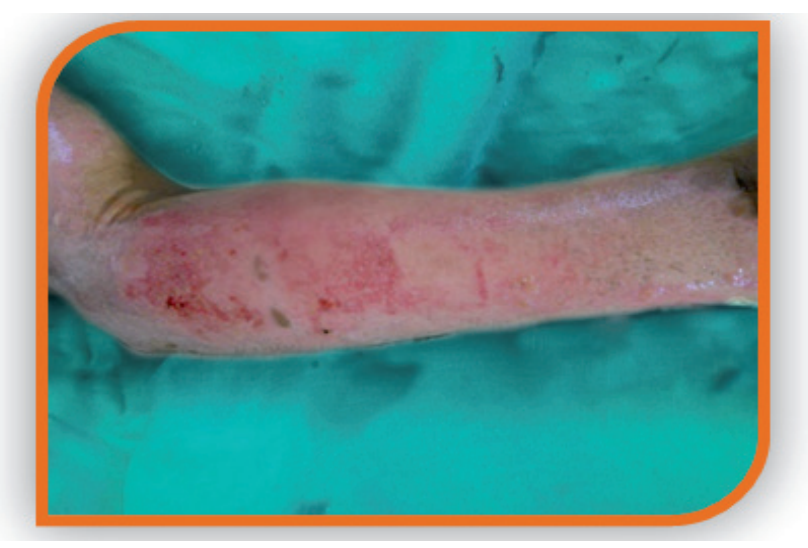

Figura 1B

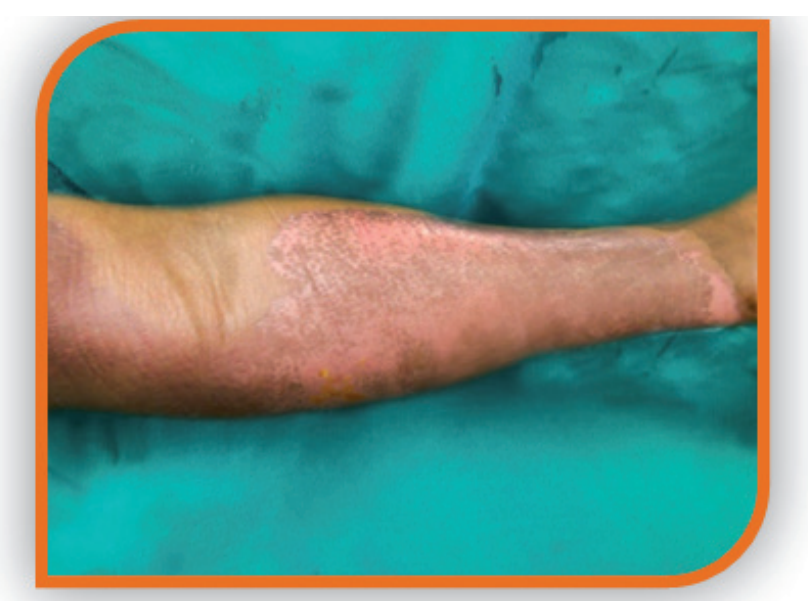

Figura 1C

Caso 2: Paciente de 42 anos, sexo feminino, queimadura por combustão de álcool, apresentando $23 \%$ de superfície corpórea queimada de segundo grau superficial e áreas 
de segundo grau profundo. Deu entrada no CTQ no dia $13 / 05 / 2014$, poucas horas após o acidente. O primeiro curativo com a associação de nitrato de cério, colágeno e alginato de cálcio foi realizado em 14/05/2014. As trocas foram em 16/05/2014 (figura 2A) em 20/05/2014 (figura 2B) e em 24/05/2014 (figura 2C), data na qual perdemos o contato da paciente por evasão do hospital. A paciente apresentou mínima dor às trocas e a equipe considerou fácil o manejo dos curativos. Não foram evidenciados sinais clínicos de infecção.

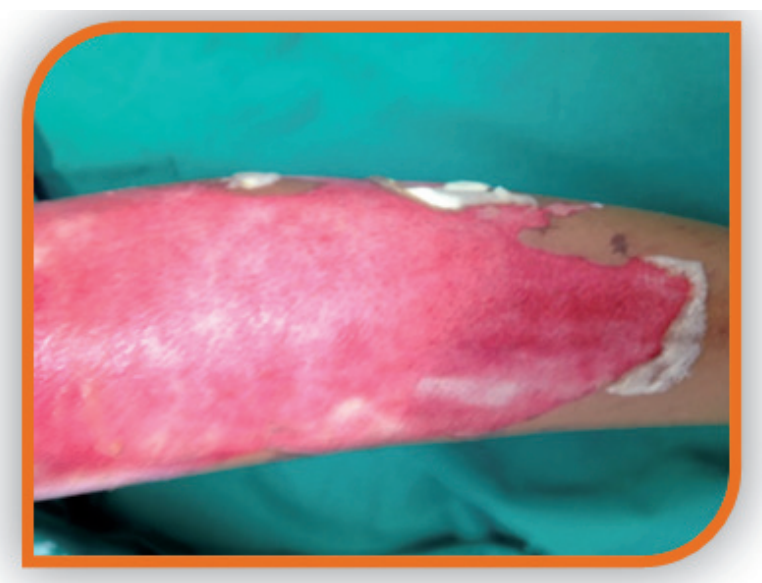

Figura 2A

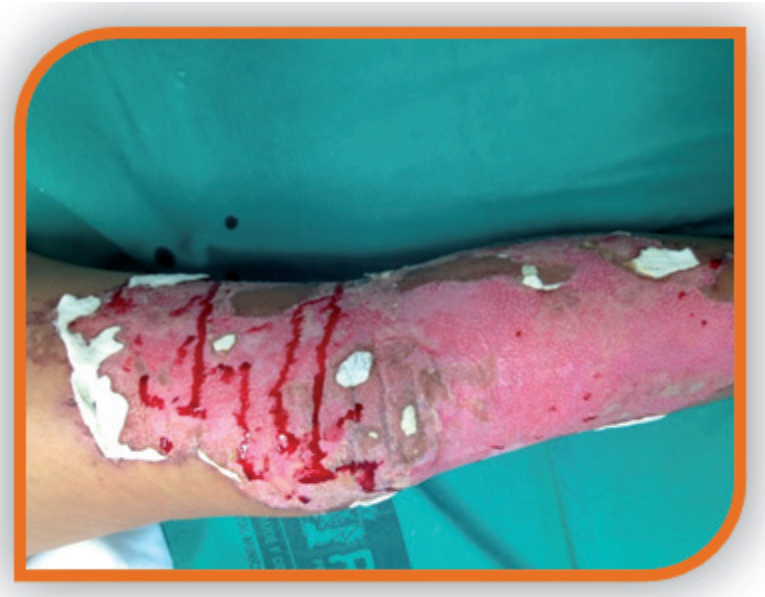

Figura 2B

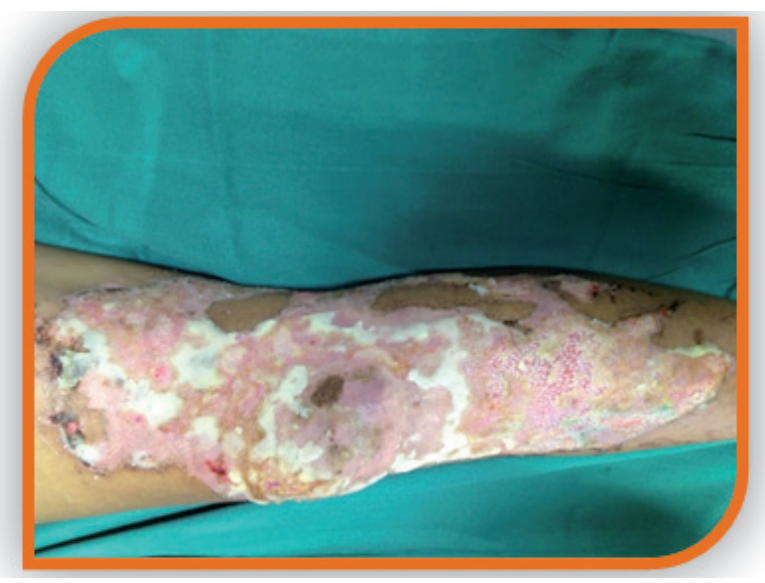

Figura 2c

Caso 3: Paciente de 20 anos, sexo feminino, vítima de queimadura por combustão de gasolina, apresentando $16 \%$ de superfície corpórea queimada de segundo grau superficial e áreas de segundo grau profundo. Deu entrada no CTQ no dia 08/05/2014. As queimaduras no antebraço e na mão direita (1,5\% da superfície corpórea total queimada) foram tratadas com a associação de nitrato de cério, colágeno e alginato de cálcio a partir do dia 14/05/2014. Os curativos subsequentes foram nos dias 16/05/2014 (figura 3A), 20/05/2014 (figura 3B) e 24/05/2014 quando observamos a completa restauração tecidual da região acometida. A observação final foi realizada no dia 27/05/2014 (figura 3C). A paciente apresentou mínima dor às trocas e a equipe considerou fácil o manejo dos curativos. Não foram evidenciados sinais clínicos de infecção.

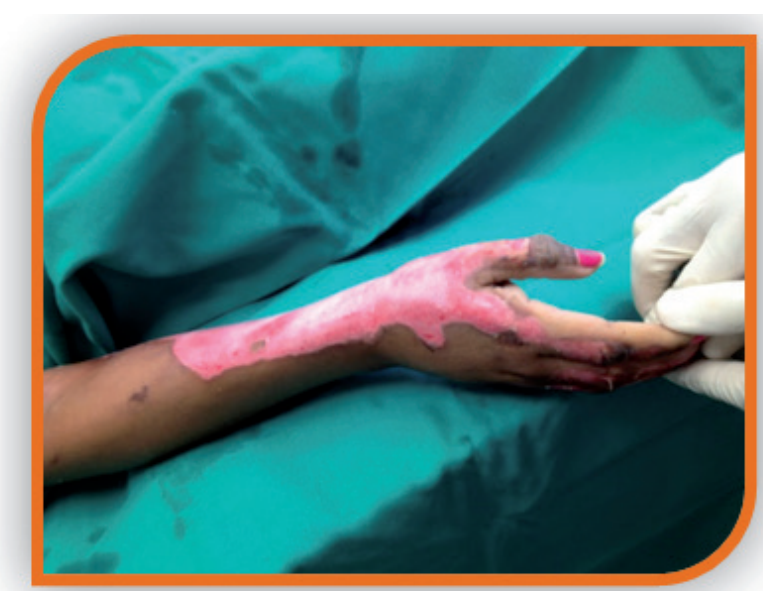

Figura 3A

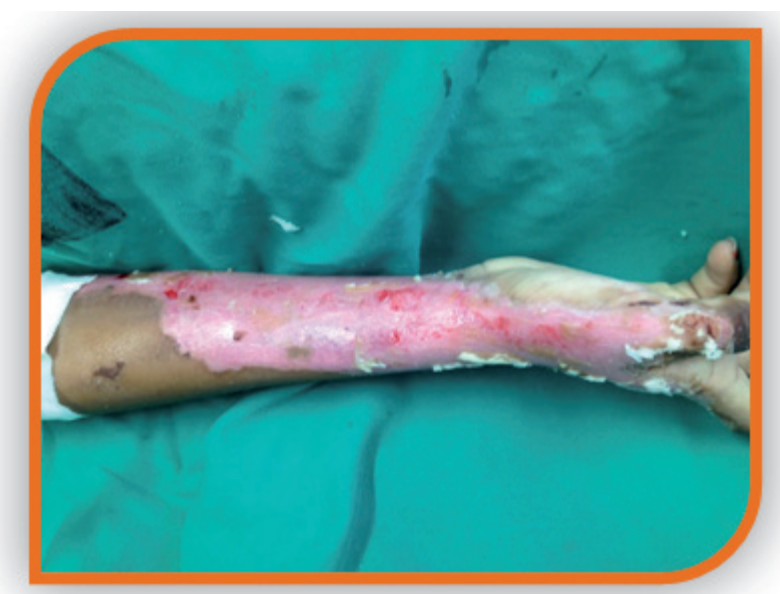

Figura 3B

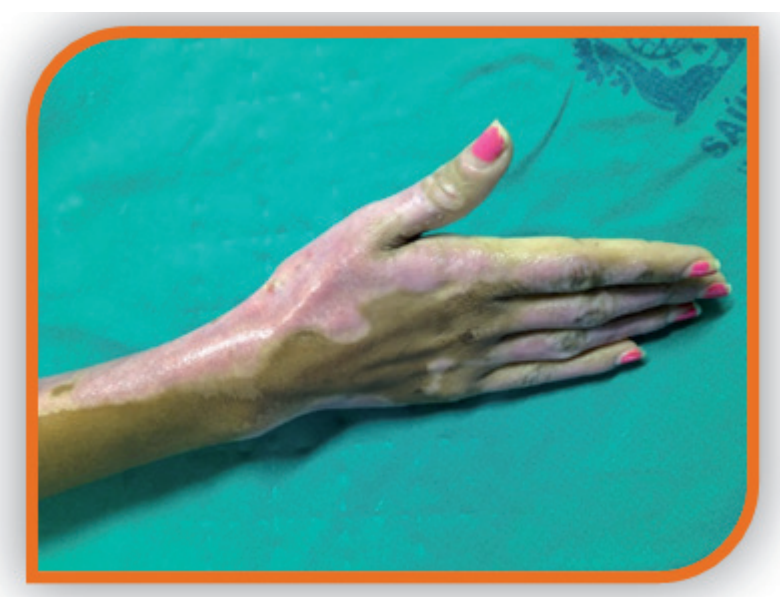

Figura 3C 
Caso 4: Paciente de 49 anos, sexo masculino, vítima de queimadura por chama, apresentando $7 \%$ de superfície corpórea queimada de segundo grau e áreas de segundo grau profundo. Deu entrada no CTQ no dia 05/12/2013, uma hora após o acidente. A queimadura de tórax posterior representando $6 \%$ da superfície corpórea total foi tratada com a associação de nitrato de cério, colágeno e alginato de cálcio a partir do dia 06/12/2013. Os curativos subsequentes foram nos dias 10/12/2013 (figura 4A), 13/12/2013 (figura 4B) e 17/12/2013, quando foi observada a total restauração da área acometida. A observação final foi realizada no dia 20/12/2013 (figura 4C). O paciente apresentou mínima dor às trocas e a equipe considerou fácil o manejo dos curativos. Não foram evidenciados sinais clínicos de infecção.

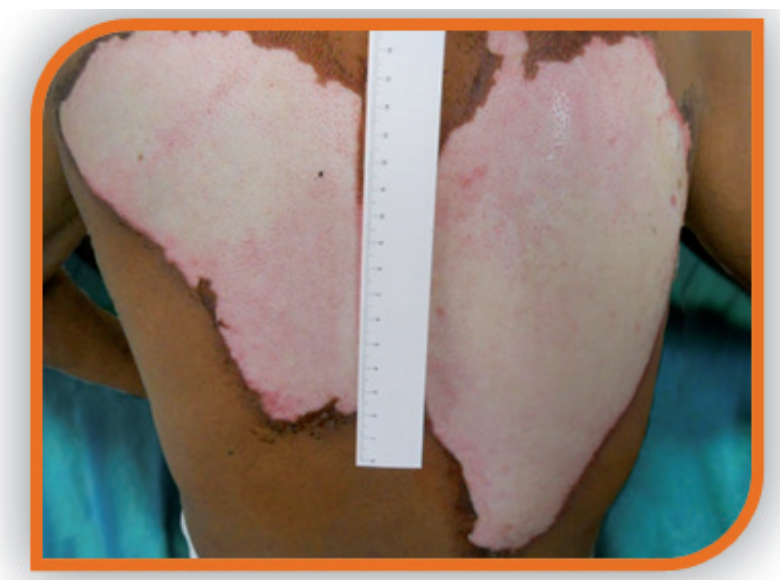

Figura 4A

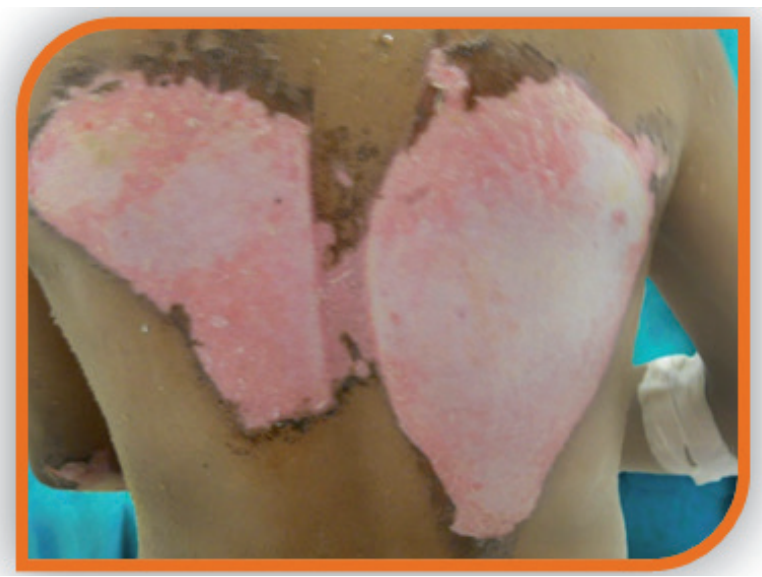

Figura 4B

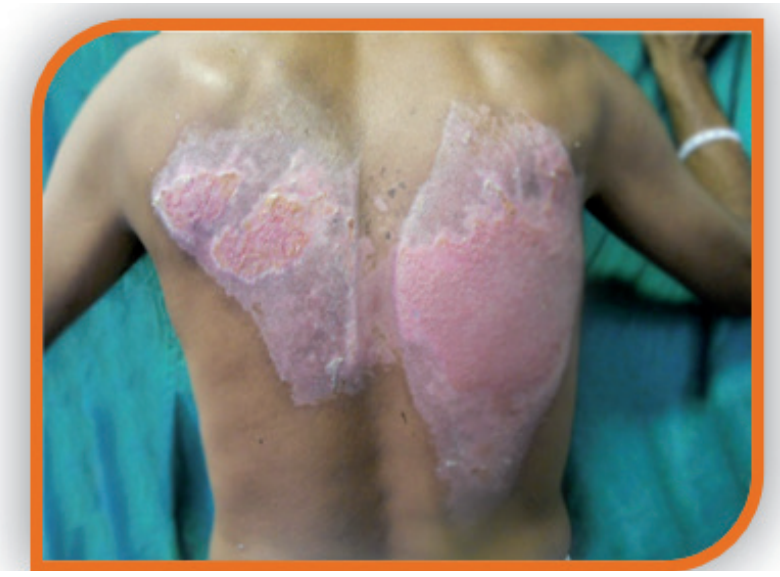

Figura 4C
Caso 5: Paciente de 18 anos, sexo masculino, vítima de queimadura por contato com escapamento de moto, apresentando $0,5 \%$ de superfície corpórea queimada de espessura total, incluindo a exposição de área tendínea. Deu entrada no CTQ no dia 05/05/2014, 24 horas após o acidente. A queimadura foi tratada com a associação de nitrato de cério, colágeno e alginato de cálcio a partir do dia 13/05/2014. Os curativos subsequentes foram nos dias 16/05/2014 (figura 5A), 20/05/2014, 24/05/2015 (figura 5B) e 27/05/2014 (figura 5C). A observação final, após a enxertia de pele, foi realizada no dia 03/06/2014 (figura 5D). O paciente apresentou mínima dor às trocas e a equipe considerou fácil o manejo dos curativos. Não foram evidenciados sinais clínicos de infecção.

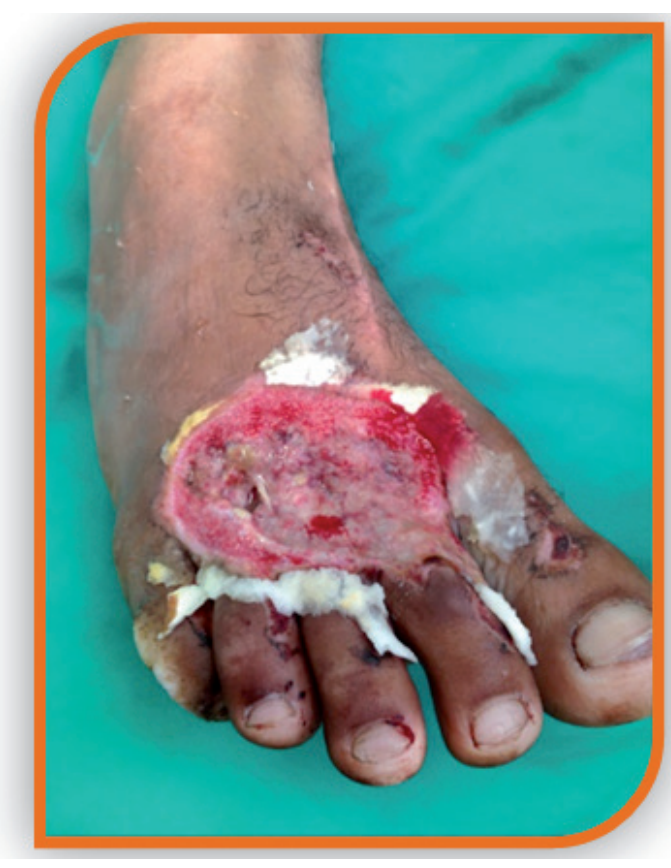

Figura 5A

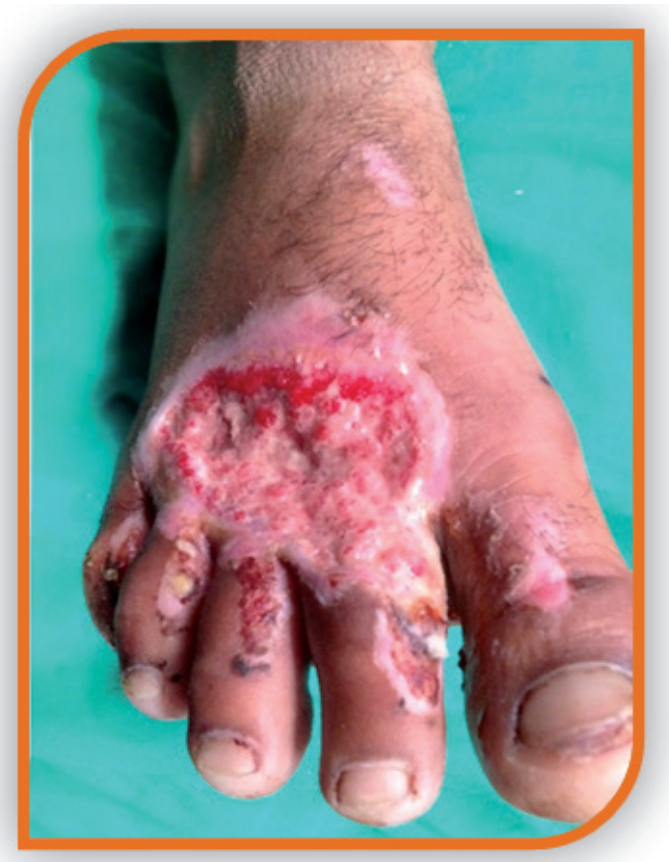

Figura 5B 


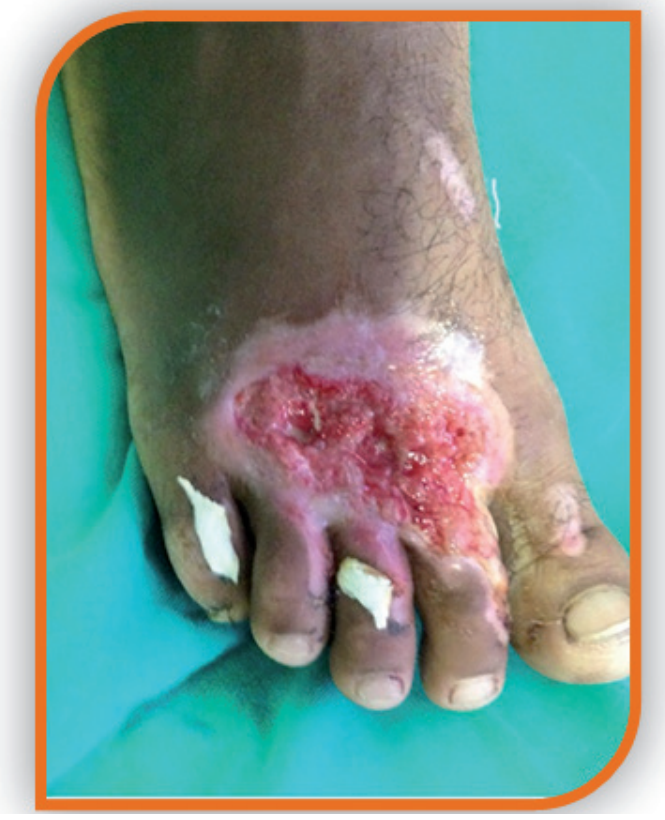

Figura 5C

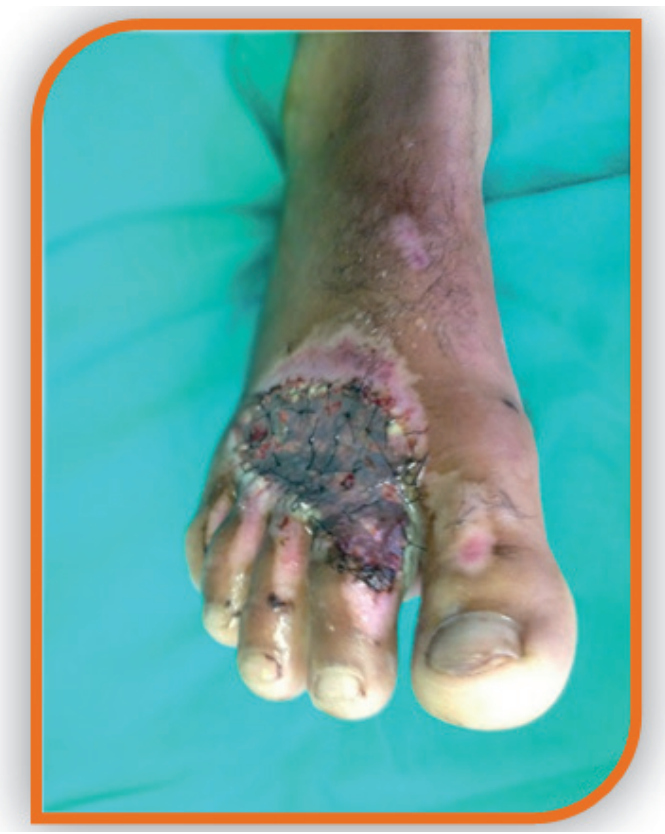

Figura 5D

Caso 6: Paciente de 31 anos, sexo masculino, vítima de dermoabrasão decorrente de acidente com motocicleta. A região acometida envolveu membro superior direito, esquerdo e hemiface direita. Deu entrada no CTQ no dia 20/01/2014, algumas horas após o acidente. A queimadura da hemiface direita foi tratada com a associação de nitrato de cério, colágeno e alginato de cálcio a partir do dia 28/01/2014. Os curativos subsequentes foram nos dias 04/02/2014 (figura 6A), 07/02/2014 (figura 6B), 11/02/2014 (figura 6C) e 14/02/2014. A observação final, após a enxertia de pele, foi realizada no dia 17/02/2014 (figura 6D). 0 paciente apresentou mínima dor às trocas e a equipe considerou fácil o manejo dos curativos. Não foram evidenciados sinais clínicos de infecção.

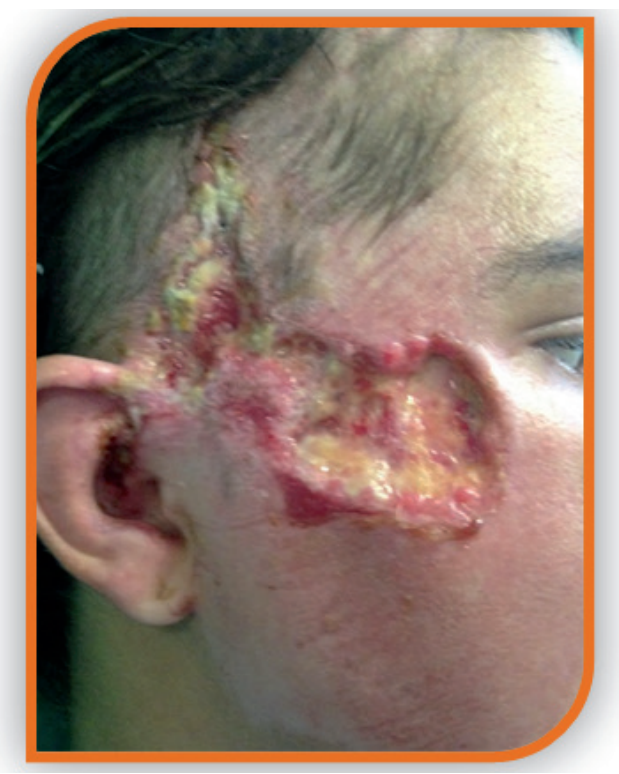

Figura 6A

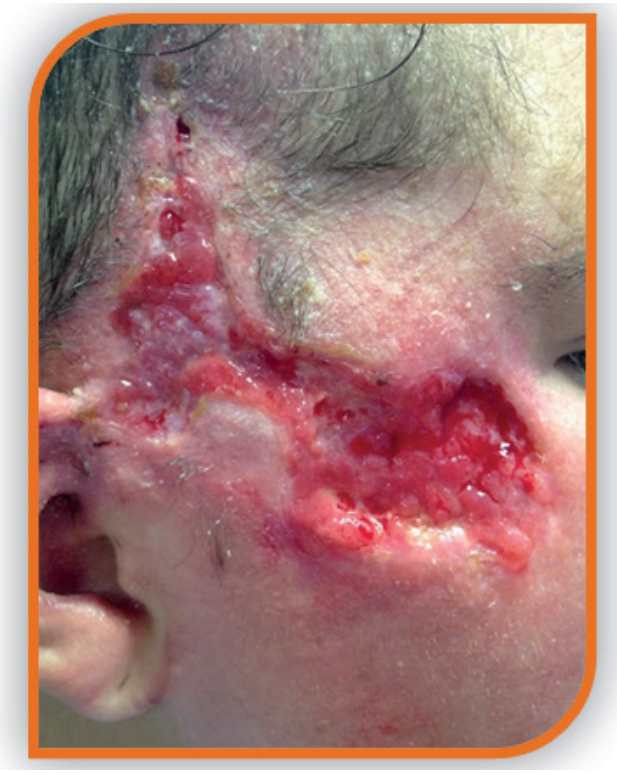

Figura 6B

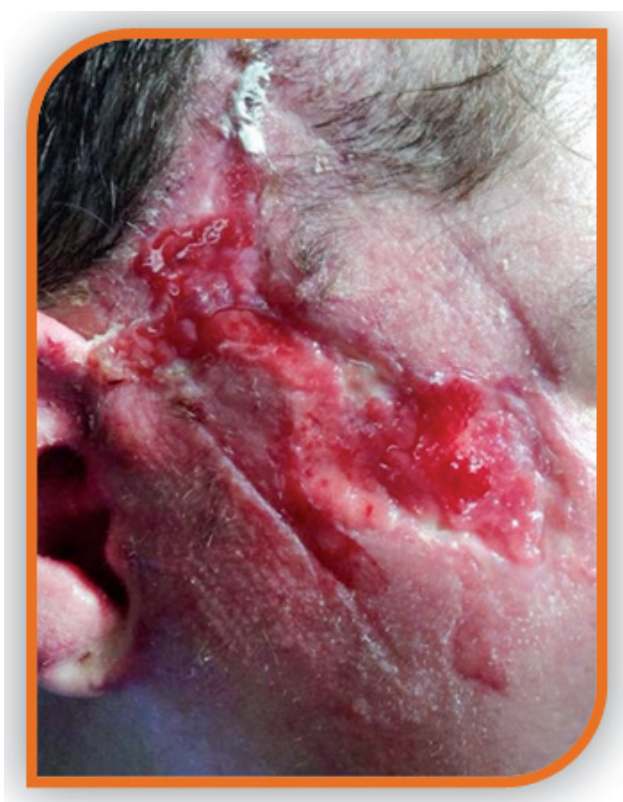

Figura $6 C$ 


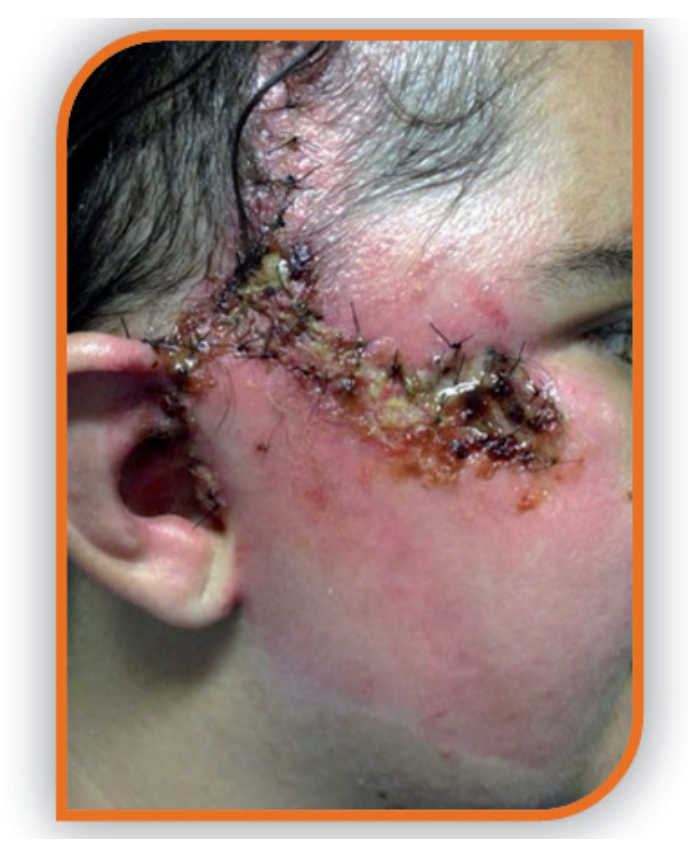

Figura 6D

\section{DISCUSSÃO}

Nesse estudo, em relação ao sexo, quatro eram do sexo masculino e dois do sexo feminino, e as idades variaram de 18 a 49 anos. Todas as queimaduras foram classificadas em segundo grau superficial e profundo.

Os agentes causadores das queimaduras foram por arco voltaico, combustão por álcool, gasolina, chama, escapamento de moto e dermoabrasão por acidente automobilístico.

Em todos os casos acompanhados as queimaduras apresentaram melhora no processo de reparo tecidual e da dor e não foram evidenciados sinais clínicos de infecção durante as trocas de curativos. Sendo que em três casos acompanhados (50\%) houve cicatrização completa no tempo de acompanhamento do estudo.

0 tratamento das queimaduras constitui um grande desafio no que diz respeito ao combate à infecção e sepse $^{7}$, dificuldades de imunomodulação ${ }^{3}$, dor, tempo de restauração e cicatrização tecidual, conforto do paciente, facilidade de trocas de curativos e maior intervalo entre as mesmas.

O curativo que associa o nitrato de cério, colágeno bovino e alginato ainda não apresenta dados de literatura para comparação com os resultados obtidos neste estudo, por ser um curativo novo. Sabemos, no entanto, que o nitrato de cério a $2,2 \%^{8}$ já tem seu uso consagrado no tratamento do grande queimado desde sua introdução no mercado europeu. Da mesma forma, a associação de colágeno bovino e alginato já existe e tem seu uso amplamente utilizado, tanto para queimaduras como para lesões crônicas. ${ }^{9,10}$

Ambos os produtos, quando comparados aos tratamentos convencionais anteriores, mostraram-se superiores, em especial no grande queimado, no que diz respeito ao nitrato de cério ${ }^{11}$, bem como nas queimaduras de segundo grau, no que diz respeito à associação do colágeno bovino e alginato ${ }^{6}$. Desse modo, a combinação de ambos os produtos, contempla os aspectos referentes à imunomodulação, infecção, redução do número de trocas (que variou de 2 a 4 dias de intervalo), mínima dor referida pelos pacientes durante o tratamento e facilidade de aplicação (manejo do curativo pela equipe).

\section{CONCLUSÃO}

O uso do curativo biológico composto por nitrato de cério, colágeno bovino e alginato de cálcio resultou na cicatrização total de $50 \%$ das queimaduras acompanhadas no estudo, melhora no processo de reparo tecidual e da dor e não foram evidenciados sinais clínicos de infecção durante as trocas de curativos.

Em detrimento do tamanho da amostra desse estudo, sugere-se a realização de estudos clínicos randomizados com amostras mais amplas, para avaliar a efetividade e eficácia desse curativo.

\section{REFERÊNCIAS}

1. Lacerda LA, Carneiro AC, Oliveira AF, Gragnani A, Ferreira LM. Estudo epidemiológico da Unidade de Tratamento de Queimaduras da Universidade Federal de São Paulo. Rev Bras Queimaduras. 2010; 9(3):82-88.

2. Gragnani A, Ferreira LM. Pesquisa em queimadura. Rev Bras Queimaduras. 2009; 8:91-6.

3. Schultz GS, Sibbald RG, Falanga V, Ayello EA, Dowsett C, Harding K, Romanelli M, Stacey MC, Teot L, Vanscheidt W. Wound Repair And Regeneration. vol. 11, n 2, Suppl 2003; 11:1-2.

4. Allgöwer M, Schoenenberger GA, Sparkes BG. Burning the largest immune organ. Burns. Vol 21. Suppl 1 pp S7-S47, 1995. Great Britain.

5. Souza AA, Mattar CA, Almeida PCC, Faiwichow L, Fernandes FS, Neto ECA, et al. Perfil epidemiológico dos pacientes internados na Unidade de Queimaduras do Hospital Servidor Público Estadual de São Paulo. Rev Bras Queimaduras. 2009; 8(3):87-90.

6. Rossi LA, Menezez MAJ, Gonçalves N, Ciofi-Silva CL, FarinaJunior JA, Stuchi RAG, et al. Cuidados locais com as feridas das queimaduras. Rev Bras Queimaduras. 2010; 9(2):54-59.

7. The American Burn Association Consensus Conference on Burn Sepsis and Infection Group; Greenhalgh DG, Saffle JR, Holmes JH IV, Gamelli RL, Palmieri TL, Horton JW, Tompkins RG, Traber DL, Mozingo DW, Deitch EA, Goodwin CW, Herndon DN, Gallagher JJ, Sanford AP, Jeng JC, Ahrenholz DH, Neely AN, O'Mara MS, Wolf SE, Purdue GF, Garner WL, Yowler CJ, Latenser BA. Journal of Burn Care \& Research. November/December 2007 - Volume 28 - Issue 6 - pp 776-790. doi: 10.1097/ BCR.0b013e3181599bc9. Special Report.

8. Garner JP, Heppell PSJ. Cerium nitrate in the management of burns. Burns. Vol 31, Issue 5, August 2005, pp 539-547.

9. Shi L, Ermis RBS, Kiedaisch BMS, Carson D. The Effect of Various Wound Dressings on the Activity of Debriding 
Enzymes. Advances in Skin \& Wound Care, October 2010 Volume 23 - Issue 10 - pp 456-462.

10. Carvalho VF, Paggiaro AO, Isaac C, Gringlas J, Ferreira MC. Clinical Trial Comparing 3 Different Wound Dressings for the Management of Partial-Thickness Skin Graft Donor Sites Journal of Wound, Ostomy \& Continence Nursing. November/ December 2011 - Vol 38 - Issue 6 - pp 643-647.

11. Gracia CG. An open study comparing topical silver sulfadiazine and topical silver sulfadiazine-Cerium Nitrate In The Treatment Of Moderate And Severe Burns. Burns. Vol 27, Issue 1, February 2001, pp 67-74. 